\title{
M.C. Escher and the Calabrian Cultural Landscape of Linguistic Greek Minorities
}

\author{
Daniele Campolo ${ }^{1, a}$
}

${ }^{1}$ Mediterranea University of Reggio Calabria - PAU - Department of Heritage, Architecture, Urban Planning, Via Salita Melissari - 89124, Reggio di Calabria, Italy

adaniele.campolo@unirc.it

Keywords: Cultural Heritage, Cultural Landscape, Enhancement, Evaluation, Historic Centers, Linguistic Minorities, M.C. Escher.

\begin{abstract}
The Calabrian Region, in the past centuries, has been a refuge land for groups of different culture and religion from various Mediterranean areas. Today in this area it is still possible to identify three major ethnic language minorities related to historical events dating back to times past: the Greek of Calabria minority in the province of Reggio Calabria, the Waldensians one in the province of Cosenza and the Arbëreshë culture in the province of Cosenza, Crotone and Catanzaro.

The existence in the same region of three "historical linguistic minorities", protected by the Law no. 482/1999, is unique in the Italian panorama: this territory is characterized by an ancient culture, an historic and architectonic heritage, and it is also inserted in an environment of great natural value, such as to create the conditions for the attempts to inclusion of this areas in the UNESCO heritage sites within the "Cultural Landscape" category.

These territories are formed hierarchically by different ecosystems, deeply influenced by various factors such as the geological composition of the soil, the microclimate, the presence of the "fiumare" (characteristic Calabrian rivers), the geographical setting difficulties for agriculture and the use of terracing techniques to overcome the lack of large flat areas. The different combinations of these micro-ecosystems creates a complex landscape that can be observed at different scales and is determined by the human management of the various natural resources.

No wonder that this landscape inspired Maurits Cornelis Escher to spend many months in this region, drawing and sketching.
\end{abstract}

\section{Introduction}

The Calabrian Region, in the past centuries, has been a refuge land for groups of different culture and religion from various Mediterranean areas. Today in this area it is still possible to identify three major ethnic language minorities related to historical events dating back to times past: the Grecanic minority in the province of Reggio Calabria, the Occitan one in the province of Cosenza and the Arbëreshë culture widespread in the province of Cosenza, Crotone and Catanzaro (Fig. 1).

The existence in the same region of three linguistic minorities protected by the Law No. 482 of 1999 "Regulations regarding the protection of historical linguistic minorities", is unique in the Italian panorama: the richness of the intangible cultural heritage of each population of these linguistic minorities combines also with a valuable natural heritage such as to have the conditions for the inclusion of the involved areas in the UNESCO World Heritage Site (in the "Cultural Landscape" category). 
The term "Cultural Landscape" was used from the end of the nineteenth century when a concept began to assert: that of the man that uses and transforms continuously the territory, adapting it to his necessities and needs.

With the evolution of the concept of landscape in "cultural landscape" also changes the idea of nature and culture, the most pervasive dualisms of Western thought.

In particular the human geographer Carl O. Sauer underlined the agency of culture as a force capable to shape and influence the visible features of the Earth's surface. The Sauer's definition of cultural landscape reads as follows: "The cultural landscape is fashioned from a natural landscape by a cultural group. Culture is the agent, the natural area is the medium, the cultural landscape is the result'. [1] (Fig.2)

\section{The cultural landscape of the Grecanic Area}

The Grecanic Area consists of those populations that historically have been identified as "grecanici" or "Greek of Calabria" which can be considered the last living witnesses of the Hellenic diaspora that

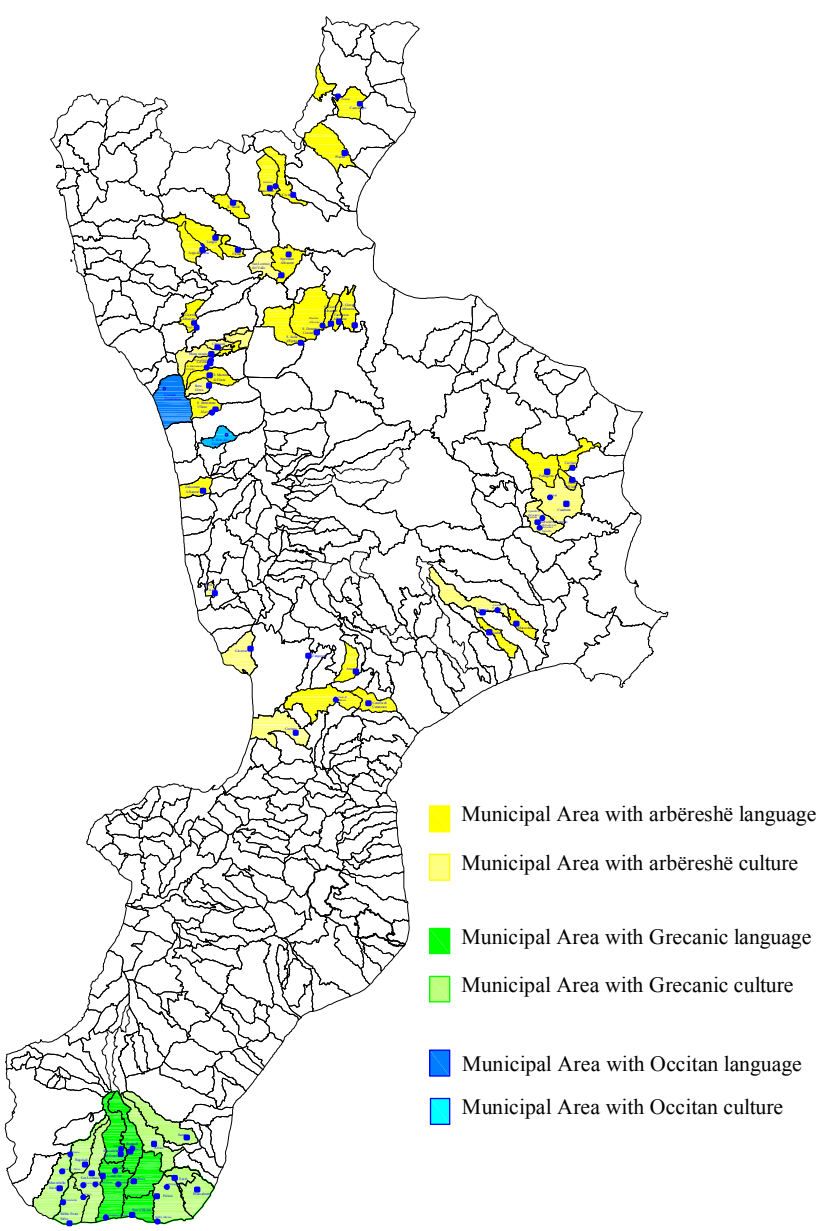

Fig. 1: Linguistic minorities of Calabria. since the eighth century B.C. colonized, in successive waves, the coasts of prehistoric, ancient, medieval and modern Calabria [2].

The Grecanic territory, located in a landscape of particular interest for its culture, presents a condition of absolute uniqueness and exceptionality in relation to the persistence of the grecanic language, a strong element of cultural identity. This language has been preserved up to now, in spite of the contamination, with the presence of a culture of ancient Greek origin.

This is an area traditionally marginalized from the large infrastructures and, of course, the difficulty of relationship with the outside world has helped to keep alive the traditional language.

For centuries this area assumed the role of cultural island for different reasons: the precarious connections with the major cities along the coast; the particularly impervious inland devoid of communication routes, if you exclude the coastal highway and the railway, built between the late 800 and early 900 , and with them a tortuous path that connected Bova Marina (Jalò you Vùa) with Bova (Vùa).

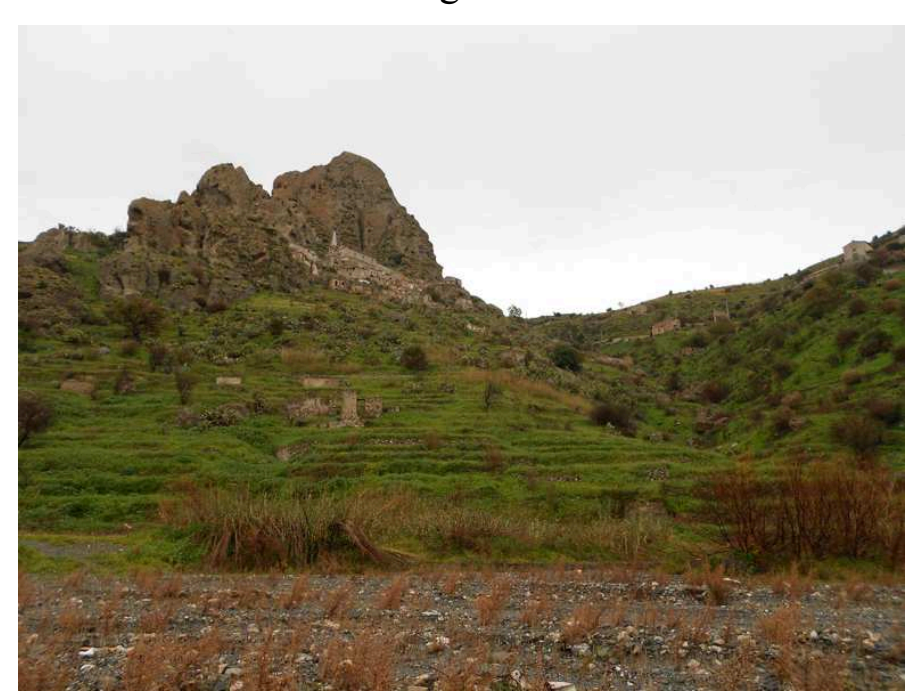

Fig. 2: The Cultural Landscape of Pentedattilo 
All roads were composed of a network of paths and trails along the floodplains of the rivers or along the ridges of the mountains. These primitive roads connected Bova, the most important economic and cultural center of the whole territory, with the hinterland, and were built along the floodplains of rivers or ridges of the mountains.

The landscape is extremely characterized by the "fiumare": waterways without source, that because of the short distance between the mountains and the coast, because of the acclivity of the slopes, the high inclination, take torrential character and high erosion capacity.

The waterways are very wide, fast-flowing during floods and low-flow in summer time: upstream of their course there are valleys and gorges carved by the impetuous flow of water, giving rise, in some places, to beautiful waterfalls.

The area is also characterized by numerous historical towns built on the tops of the mountains, where, from the seventh century B.C., some groups of Greek settlers built their cities.

The historical centers, today in the medieval town planning, were built in a defensive position to protect the inhabitants from the incursions of Saracens; these cities are camouflaged in the landscape and are almost invisible from the coast; they have a visual domain over the surrounding territory up to the sea; they were visible each other, but separated by valleys and rivers. The reason for this geographic positioning is not only to be detected in a defensive need but also in an easier water supply and protection from malaria that infested the coastal wetlands (Fig. 3).

The rivers have influenced the settlement pattern of these territories, in fact many of the inhabited centers are located close to the river-beds which are, at the same time, a mean of communication to the coast, a source of water supply for the irrigation of the fields, a reserve of building materials and a level place to grow. It is therefore evident the enormous importance that these waterways have taken to the local communities: they have been at the same time a mean of communication and a separating agent between the different centers, because they were impractical for long periods of the year and they have made also a pole of attraction

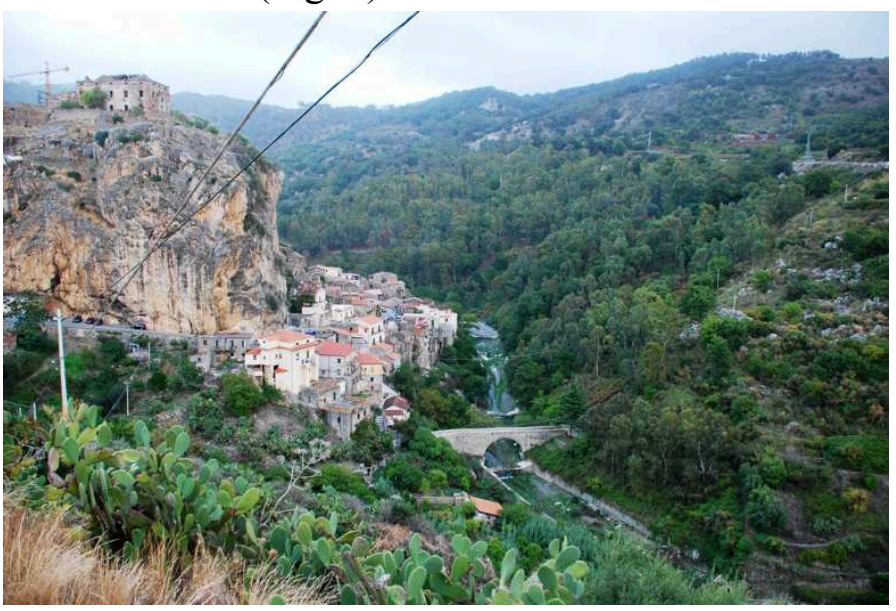

Fig. 3: Historic Center of Palizzi, the fortress and the "fiumara" for many economic activities such as irrigation of crops. Sometimes works of high hydraulic engineering were implanted on their secret and they were allowed to take advantage of the potential energy of the water for operations like mills and olive-press.

The territory has a cultural heritage that has been underestimated for many years: rich in rivers and ravines, it has features rock shapes, formed primarily of natural conglomerates, where the wind and water have given special shapes, as if they were architectural works or very evocative sculptures. These natural sculptures have special names, such as "Ta vrastarùcia" (boilers of milk) "I Ròcca tu Dràgu" (the fortress of the Dragon), or the Rock of Pentedattilo.

No wonder that this landscape, with its villages perched on the top of the mountains, inspired Maurits Cornelis Escher to spend many months in this region, drawing and sketching.

M. C. Escher (1898-1972) was one of the world's most famous graphic artists, known primarily for his often mathematically inspired woodcuts, lithographs, and mezzotints. In fact he is famous for his so-called "impossible constructions".

Escher traveled in Calabria, from April 28 to May 25, 1930, accompanied by three friends: he arrived to Pizzo by train, and then went to Tropea, Scilla, and Mélito. At that point the travellers followed mule trails and dried-out river beds until they reached Pentedattilo, where they stayed for a 
few days. Then they moved on to Palizzi and Stilo, Crotone, Santa Severina and Rossano, Morano Calabro and Rocca Imperiale [3].

In this time Escher produced several prints, lithographs and woodcuts. Right in the "Italian time", the natural world was central element of his work: the animals, the birds and the breathtaking perspectives of the landscapes have been his greatest source of inspiration for years.

Escher travelled through the most inaccessible places in Calabria: the landscape and nature were the two elements that continued to fascinate him for the rest of his life. In particular, in the Grecanic Area, Escher and his friends were forced to follow paths with a mule, so they've been able to reach some villages in the foothills of the Aspromonte including Palizzi and Pentadattilo. This is a charming and picturesque village that was built in the heart of a rock, it was abandoned in the eighties, and it is now one of the most beautiful "ghost towns" of Calabria. Such is its beauty that Escher created many drawings of Pentedattilo's sights from which he created four incisions.

It is indeed amazing that after all these years, the villages, streets, and landscapes that M.C. Escher drew, have not changed at all. Of course, not everything has stood still: flats have been built, more houses have been added, roads have been paved, but mostly the landscape hasn't changed that much.

The particular villages of southern Calabria, perched above characteristics rock formations, were perfect for him. Escher experimented different types of perspective by choosing an unusually high or low vantage point to draw from: in some cases he selected an extremely low vantage point, like valley. As a result, the viewer looks up at an object located far above: this is known as the "frog's perspective". In other works Escher chose a very high vantage point: in these works the viewer looks down with a different perspective, known as the "bird's eye" perspective.

Escher was constantly imagining new combinations to surprise the viewer; he wanted to "draw attention to something that is impossible": and in order to achieve this, "there has to be a degree of mystery, but one that isn't immediately apparent". He even spoke of "trickery": one of the means he used to this end was a combination of different sightlines within the same work.

To photograph Pentedattilo from the same viewpoint, at which Escher must have sketched the drawings for his lithograph, you must climb slopes and you must ascend through bushy hills with brambles bushes and prickly pears, but then you get this spectacular view of Pentedattilo.

It is all still there: the Rock, the castle, the Church of SS. Pietro e Paolo, the same houses, but more then 80 years have passed and it looks like the world has stood still.

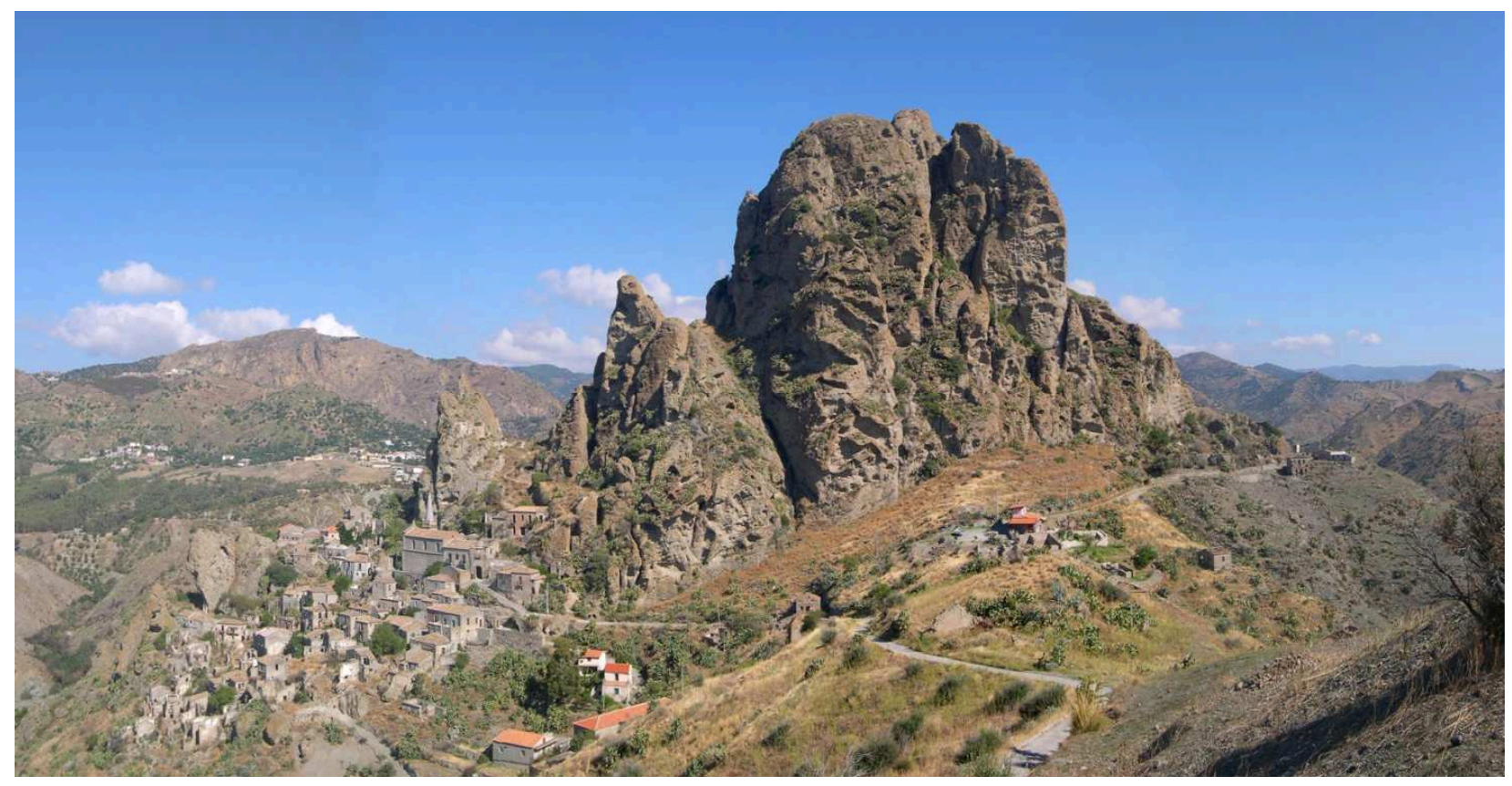

Fig. 4: Pentedattilo's panorama from the same viewpoint of Escher's lithograph 
It is a maze of small alleys and steps, seemingly without rationale urban plan. One house is constructed, so it looks on top of another. The roof of one house is actually the floor of another. Alleys wind themselves underneath the various houses and seem to stop, only to continue after climbing some further steps. It is like walking in a huge labyrinth.

\section{Conclusions}

In the last few years the landscape has been considered a very important public good to protect and to enhance, but at the same time it can also become an economic resource, a source of wealth useful to respond to different needs (economic, social, cultural and environmental needs) of the communities. In particular the landscape is an economic resource for the inland areas of Calabria, who suffer from depopulation and abandonment, it is a resource non-reproducible and therefore it must be used in a sustainable way.

The cultural landscape can be used for tourism purposes but with the due attentions: tourism, which has become a mass phenomenon, causes an ever greater consumption of resources, especially those that were considered the most beautiful and rare. On the other hand the landscape can be used as a resource for local development but it must arouse an "objective" interest.

The balance between human habitat and the natural environment must be guaranteed and it should trigger a process of reorganization of the urbanized environment, exerting a continuous control over the components that might upset this balance. The relationship with nature changes with the human changing, with the changing of human culture, of human needs and of human behavior. The development model of the present city was founded on the exploitation of non-renewable resources and on the waste of renewable resources, this will lead to imbalances, often irreversible, that affect the ecosystem as a whole. The conservation of resources, primarily of non-renewable resources, is a necessary condition to define development models based on the compatibility between the needs of man and the vocations of the natural environment.

The enhancement of a similar area can start with a good activity of historical knowledge of the territory with meticulous census and catalogue of the historical, environmental, cultural, landscape resources: the territory becomes a written document which must be read in all its details and also becomes historical memory of earlier cultures.

Therefore recovery and/or safeguard actions cannot ignore the sense of belonging to a cultural territory of the people who inhabit it. People should be aware that their culture is an asset to the future of the community. Once the landscape is abandoned or not recognized as element of identity of the community, it is inevitable the deconstruction of the landscape resulting in the "naturalization" to a neutral environment.

The values of the local culture should be "re-actualized" in the area otherwise any restoration and enhancement interventions of a cultural landscape could become a "museumification" action.

The "recognition" of the cultural landscape as a resource can become a driving force for the economic development of a territory [5].

The communities of this cultural landscape can receive maximum benefits from the existing cultural and ecological systems in terms of sustainability: from the point of view of economic production, of the safeguard of the territory and of the increase in quality of life. 


\section{References}

[1] C. Sauer: The Morphology of Landscape, in University of California Publications in Geography. N. 22, (1925) pp. 19-53.

[2] D. Campolo: The Cultural Landscape of Linguistic Minorities in the Calabrian Region: Cultural Premises for Intervention and a Study Case in the Grecanic Area, In: SOCIETY, INTEGRATION, EDUCATION Utopias and dystopias in landscape and cultural mosaic. Visions Values Vulnerability Proceedings of the International Scientifical Conference June 27th - 28th, 2013 Volume III. SABIEDRIBA, INTEGRACIJA, IZGLITIBA, vol. III, pp. 39-48, ISSN: 1691-5887, Udine, 27-28 Giugno 2013.

[3] J. L. Locher: Il mondo di Escher. Garzanti, 1978.

[4] L. Della Spina, F. Calabro', L. Sturiale: Cultural planning: a model of governance of the landscape and cultural resources in development strategies in rural contexts. In: SOCIETY, INTEGRATION, EDUCATION Utopias and dystopias in landscape and cultural mosaic. Visions Values Vulnerability Proceedings of the International Scientifical Conference June 27th - 28th, 2013 Volume V. SABIEDRIBA, INTEGRACIJA, IZGLITIBA, vol. V, ISSN: 1691-5887, Udine, 27-28 Giugno 2013.

[5] D. Campolo: Il Bene Culturale come risorsa economica: aspetti metodologici, in A. Bianco (a cura di), Articolo 9, Roma: Aracne Editrice, pag. 33-52, Isbn 978-88-548-6804-5, DOI $10.4399 / 97888548680452$ 